\title{
Gênero e Sexualidade no Sul Global: Um olhar para feminismos africanos sob a perspectiva pós-colonial
}

\author{
Walkis Stwart ${ }^{1}$
}

\section{Resumo}

O presente trabalho propõe apresentar, através de abordagem teórica e histórica, estudos acerca das questões de sexualidade e especialmente de gênero no que diz respeito aos movimentos feministas, tanto no Norte quanto no Sul global, utilizando-se da perspectiva póscolonial para apontar gênero e sexualidade como alvos de uma matriz de poder sociocultural que se sustenta sobre as colonialidades. Neste sentido, busca-se apresentar de forma geral diversas abordagens acerca das questões de gênero e sexualidade num plano cronológico e entendido em vários campos teóricos científicos. Foram abordados algunsmovimentos feministas em África com o objetivo de apontar relações de colonialidades presentes no contexto dos movimentos feministas entre o Norte e o Sul global.

Palavras-chave:Gênero; Sexualidade; Colonialidades; Feminismos; Pós-colonialismos.

\section{Abstract}

This paper presents, through a theoretical and historical approach, studies about the issues of sexuality and especially of gender with regard to feminist movements, both in the North and in the global South, using the postcolonial perspective to point out gender and sexuality as targets of a sociocultural power matrix sustained under colonialities. In his sense, it sought to present in a general way different approaches on the issues of gender and sexuality in a chronological plan and understood in several scientific theoretical fields. Some feminist movements in Africa were approached with the aim of pointing out the relations of colonialities present in the context of feminist movements between the global North and South.

Key-words: Gender; Sexuality; Colonialities; Feminisms; Post-colonialisms.

\section{Introdução}

O sistema-mundo capitalista de dominação ocidental engessado no projeto de modernidade continua reproduzindo assimetrias das mais diversas, entre o Sul e o Norte global, que beneficiam apenas esta parte do globo em detrimento da outra. $\mathrm{O}$ atual padrão global de poder instituído pelo projeto de modernidade europeia e sustentado pela matriz

\footnotetext{
${ }^{1}$ Bacharel em Relações Internacionais pela Asces-Unita e Mestrando em Relações Internacionais pela UEPB.Email: walkis.stwart@gmail.com.
} 
colonial do poder, conceito definido por Quijano, se deu através de um embrutecido processo de colonização nas Américas, e sobretudo em África, que subalternizou povos, desconstruiu identidades e colonizou corpos e mentes no Sul global.

A colonialidade do poder enraizada no sistema mundo moderno foi responsável pela mais profunda e eficaz forma de dominação social, material e intersubjetiva que se caracterizou na forma mais universal de dominação política, exercendo controle sobre gênero, sexualidade, trabalho e subjetividade. A colonialidade do poder instituiu um sistema mundo moderno, capitalista, patriarcal, heteronormativo, machista e racista, lançando paradigmas eurocêntricos hegemônicos fundados nessa lógica colonial que assumem caráter universalista e neutro.

Levando em consideração que os movimentos feministas ocidentais surgem dentro deste contexto eurocêntrico, acaba sendo de extrema importância questionar suas bases epistemológicas para se compreender quais fatores são afetados e até mesmo hierarquizados na lógica representativa do feminismo enquanto movimento emancipatório, buscando assim identificar as diferenças coloniais estabelecidas entre o Norte e o Sul global.

\section{Teoria Pós-colonial}

A chegada do século XX foi carregada de uma complexa e intensa mudança nas relações internacionais:que foram de caráter político, econômico, social e também cultural. Foi um processo de mudanças que implicou uma nova divisão internacional do trabalho, uma transnacionalização da produção e do consumo, bem como a fragmentação e disseminação das culturas. Foi um processo que acarretou o multiculturalismo, o enfraquecimento das fronteiras e a alteração do regimebipolar, anteriormente imperial (ELÍBIO; ALMEIDA; LIMA, 2013).

Diante de tal contexto, acima apontado, se faz necessário reconhecer a descolonização da África e Ásia como um momento crucial do ponto de vista geopolítico, visto que este processo acaba por marcar uma profunda mudança no cenário internacional como a libertação de mais da metade da população mundial do domínio e julgo direto dos europeus e a diáspora dos povos, que formaram um fluxo migratório, reproduzindo as rotas coloniais. Assim, os pós-colonialismos ${ }^{2}$ tomam como objeto de estudo os fenômenos

\footnotetext{
${ }^{2}$ Entende-se pela carga teórica proveniente de estudos literários e culturais que ganharam visibilidade a partir dos anos 1980 em algumas universidades dos Estados Unidos e da Inglaterra.
} 
decorrentes do período pós-colonial ${ }^{3}$, para então buscar melhor compreender este novo cenário político (ELÍBIO; ALMEIDA; LIMA, 2013).

As ciências sociais vêm sendo repensadas por várias correntes de pensamento crítico que visam analisar o sistema mundo atual, a partir de epistemologias outras que sirvam para interpretar diferentes temporalidades e localidades de poder, bem como de conhecimento. Assim o faz a abordagem descolonial, proposta que surge nas áreas da Sociologia, História e Economia Política, e recentemente nas Relações Internacionais (FONSECA; JERREMS, 2012).

O pensamento descolonial é impulsionado pela América Latina através do projeto conhecido como modernidade/colonialidade/decolonialidade que faz uma chamada a um olhar mais crítico e analítico para a modernidade europeia acerca das colonialidades do ser, do poder e do saber na América e seus efeitos sobre sujeitas (os) coloniais globais (FONSECA; JERREMS, 2012).

As perspectivas pós-coloniais compartilham do caráter discursivo do social, da descentralização das narrativas e de sujeitos contemporâneos, do método da desconstrução dos essencialismos, e principalmente da proposta de uma epistemologia ${ }^{4}$ crítica às concepções dominantes da modernidade. O colonialismo refere-se a relação de opressões diversas a partir de fronteiras de gênero, etnia ou raça (COSTA, 2006 apud BALLENSTRIN, 2013).

Tendo reforçado as ideias da literatura clássica, alavancando o arcabouço teórico pós-colonial, surgiu no sul asiático, na década de 1970, o grupo de Estudos Subalternos movimento intelectual que diz respeito a crítica da modernidade a partir do Sul global - e que inspirou mais tarde, a formação do grupo Latino-americano de Estudos Subalternos em 1992, movimento que faz a crítica a modernidade a partir do Norte global (BALLENSTRIN, 2013; GROSFOGUEL, 2008).

Já o pensamento decolonial,surge como crítico dos Estudos Subalternos. O termo é cunhado por Nelson Maldonado-Torres em 2005, e refere-se a um movimento de resistência teórico e prático, político e epistemológico à lógica da modernidade/colonialidade. Como afirma Mignolo (2003), o pensamento decolonial é uma elaboração posterior aquilo que ele chama de pensamento fronteiriço ${ }^{5} \mathrm{e}$ que resiste a modernidade, ao cristianismo, ao liberalismo, ao marxismo, ao conservadorismo e ao colonialismo.

\footnotetext{
${ }^{3}$ Refere-se ao tempo histórico posterior a descolonização do chamado "Terceiro Mundo", a partir da metade do século XX.

${ }^{4}$ Refere-se ao entendimento acerca da produção do conhecimento, a sua relação entre agente e objeto.

${ }^{5} \mathrm{O}$ pensamento fronteiriço, desde a perspectiva da subalternidade colonial, é um pensamento que não pode ignorar o pensamento da modernidade, mas que não pode tampouco subjugar-se a ele, ainda que tal pensamento
} 
Para se fazer cumprir este processo de resistência colonial sustentado em uma proposta de descolonizar o pensamento e romper com a lógica monológica da modernidade,Dussel (2000) traz a ideia de transmodernidade, projeto de libertação político, econômico, ecológico, erótico, pedagógico e religioso. A transmodernidade vem a ser um chamado para um novo olhar sobre a modernidade/colonialidade de forma crítica partindo da perspectiva de múltiplas experiências de sujeitos que sofrem de distintas formas as colonialidades do poder, do saber e do ser (MALDONADO-TORRES, 2007, p.162).

Como afirma Mignolo (2003), a colonialidade se reproduz a partir dessas três dimensões, do poder, do saber e do ser, sendo ela o lado obscuro e necessário da modernidade e portanto sua parte indissociavelmente constitutiva. A colonialidade do poder, conceito originalmente desenvolvido por Aníbal Quijano, em 1989, exprime a constatação de que as relações de colonialidade nas esferas econômica e política não cessaram com o fim do colonialismo (GROSFOGUEL, 2008). Segundo Mignolo (2010), a matriz colonial do poder apresenta uma estrutura complexa de níveis entrelaçados que abarca o controle da economia, da autoridade, da natureza e seus recursos, do gênero e da sexualidade, da subjetividade e do conhecimento.

A colonialidade do saber diz respeito a ideia de dominação epistêmica. Essa ideia foi desenvolvida por Boaventura de Sousa Santos, se utilizando do conceito de pensamento abissal, no qual o autor defende que a colonialidade/modernidade concede à ciência moderna o monopólio da distinção entre aquilo que é verdadeiro e falso. A colonialidade se entende, portanto, como uma experiência heterogênea em que existem múltiplas formas de subalternização (JERREMS; FONSECA, 2012).

Segundo Aníbal Quijano (2007), podemos definir o atual sistema mundo como um aparato histórico-estrutural heterogêneo, dotado de uma matriz colonial a qual ele chama de "matriz de poder colonial", que afeta todas as dimensões da existência social, como sexualidade, autoridade, subjetividade e trabalho.

De acordo com Grosfoguel (2008), o patriarcado europeu, bem como as noções europeias de sexualidade, epistemologia e espiritualidade foram disseminadas por todo o mundo através da expansão colonial, transformadas assim em critérios hegemônicos que viriam a racializar, classificar e patologizar toda a população a partir de uma hierarquia de raças superiores e inferiores.

moderno seja de esquerda ou progressista. O pensamento fronteiriço é o pensamento que afirma o espaço de onde o pensamento foi negado pelo pensamento da modernidade, de esquerda ou de direita (MIGNOLO, 2003, p. 52). 


\subsection{Gênero, sexualidade e Pós-colonialidade}

Segundo McClintock (2010 apud SANTOS; SILVA, 2014), o gênero, a sexualidade e a pós-colonialidade são elementos constituintes de uma histórica e hierárquica relação de poder, que está baseada em alteridades conflitivas e na dominação colonial. Nos países latinoamericanos, embora de maneiras diferenciadas, foram naturalizadas concepções e práticas sociais profundamente marcadas pelo heterossexismo, pelo patriarcalismo, e pela heteronormatividade (LUGONE, 2007 apud SANTOS; SILVA, 2014). Tais fatores provocaram processos de estigmatização, estereotipização e marginalização de cosmologias nativas latino-americanas que lidavam diferencialmente das cosmologias europeias em relação as dimensões de gênero e sexualidade, e acarretaram e justificaram verdadeiros epistemicídios (SANTOS, 2003 apud SANTOS; SILVA, 2014).

Segundo Lugones (2014), a dicotomia central da modernidade colonial é a hierarquia dicotômica entre humano e não ser humano. Começando pela América e Caribe, essa dicotomia foi imposta sobre os colonizados e colonizadas a serviço do homem ocidental. Enquanto só os civilizados eram classificados como homem ou mulher, os povos indígenas das Américas e os africanos escravizados eram classificados como espécies não humanas, animais, incontrolavelmente sexuais e selvagens (LUGONES, 2014).

A imagem do homem europeu, burguês, colonial moderno se tornou a de um agente, apto para a vida pública e o governo, um ser de civilização, heterossexual, cristão, dotado de razão. Já a mulher europeia burguesa não era entendida como seu complemento, mas como alguém que reproduzia raça e capital por meio de sua pureza sexual, passividade, e também por estar atada ao lar a serviço do homem branco europeu burguês (LUGONES, 2014).

A transformação civilizatória, portanto, justificava a colonização da memória, das noções de si das pessoas, da relação subjetiva, da relação com o mundo espiritual, com a terra e com o próprio tecido de sua concepção de realidade, identidade e organização social. A medida que o cristianismo tornou-se o instrumento mais poderoso da missão de transformação, a normatividade que conectava gênero e civilização concentrou-se no apagamento de práticas comunitárias ecológicas, saberes de cultivo, de tecelagem, de cosmo, e também na mudança e controle de práticas sexuais e reprodutivas (LUGONES, 2014).

\section{Gênero: uma perspectiva histórica ocidental e periférica}


Segundo Stolcke (2004), o termo gênero teria surgido nos Estados Unidos em 1950 nas áreas da psicologia e sexologia. Nesta mesma época, a medicina nos Estados Unidos se posicionava contra as cirurgias para mudança de sexo, mas em 1952, Christine Jorgensen da Dinamarca se submeteu a uma mudança de sexo. Foi nesse contexto que se estabeleceram as primeiras clínicas de gênero nos Estados Unidos e psicanalistas, médicos e psicólogos adotaram o termo "gênero" para diferenciar o sexo social do anatômico, buscando solucionar as dificuldades conceituais e terminológicas que surgiam com pessoas intersexos ${ }^{6}$, transexuais ${ }^{7}$ e homossexuais, cujo sexo biológico não condizia com o sexo de nascimento ou com sua identidade sexual desejada ou orientação sexual.

Para Stolcke (2004), a ideia de que não existem mais de dois sexos está profundamente associada a cultura ocidental e a profissão biomédica não tem dúvida de que a identidade feminina e masculina são as únicas opções naturais para os intersexos. São estes antecedentes bioculturais do conceito de gênero que dão lugar ao debate de gênero na teoria feminista.

De acordo com Scavone (2008), o conceito de gênero foi construído por estudiosas da língua inglesa, como por exemplo, Gayle Rubin, antropóloga e feminista. Em um de seus primeiros textos sobre a questão que se tornaram clássicos na área, "The Traffic in Women: Notes onthePoliticalEconomyof Sex", a autora reitera a ideia de que gênero é uma divisão dos sexos imposta socialmente e produzida nas relações sociais da sexualidade, compondo o que ela denomina de sistemas de sexo/gênero.

Segundo Mary Nash (apud SOIHET, 1997), o debate em torno da opressão sobre a mulher ao longo da História teria seu início nos anos 1940, quando Mary Beard, historiadora norte-americana em sua obra "Woman as Force in History" abordou a questão da marginalização da mulher nos estudos históricos. A autora atribuiu as escassas referências à mulher ao fato de a grande maioria dos historiadores, sendo homens, terem ignorado o papel e as mulheres enquanto sujeitas da História, de forma sistemática.

Por sua vez, a historiadora Joan W. Scott introduz o conceito de gênero na História com seu famoso artigo "Gender a UsefulCategoryofHistoricalAnalysis", publicado em 1986. Nele a autora dialoga com autores pós-estruturalista como Michel Foucault, Gilles Deleuze e critica com eles a ideia iluminista da existência de um sujeito único universal com

\footnotetext{
${ }^{6}$ Designa uma variedade de condições em que uma pessoa nasce com uma anatomia reprodutiva ou sexual que não se encaixa na definição típica de sexo feminino ou masculino.

${ }^{7}$ Condição de uma pessoa cuja identidade de gênero difere daquela designada no nascimento a partir do sexo biológico e se submete a redesignação sexual.
} 
características biológicas consideradas a-históricas, que fundamentam os discursos da dominação masculina (SCAVONE, 2008).

Segundo Stolcke (2004), o termo gênero tem sido um elemento muito importante para a teoria e a política feministas desde os anos de 1970, em seus combates contra o sentido comum sexista e androcêntrico $^{8}$ que prevalece na academia e sociedade ocidentais. O objetivo era mostrar que a biologia não trazia respostas e soluções para as questões de gênero e sexualidade, mas apontar que as identidades sócio-simbólicas, por serem culturais, são variáveis e, portanto, passíveis de transformação.

Segundo Soihet (1997), enquanto campo de estudo, existe uma certa unanimidade em considerar a história das mulheres como tendo sido um movimento recíproco, de um lado da atuação das historiadoras e de outro dos movimentos feministas, que teve seu início a partir dos anos 1960.

\subsection{Teoria Queer}

A Teoria Queer emerge nos Estados Unidos, ao final da década de 1980, em oposição crítica aos estudos sociológicos em torno das chamadas minorias sexuais e gênero. Tendo como objeto de análise a dinâmica da sexualidade e do desejo nas organizações sociais, a Teoria Queer surge em departamentos normalmente não associados às investigações sociais, como os de Filosofia e crítica literária, e ganha reconhecimento a partir de algumas conferências em Universidades da IvyLeague (MISKOLCI, 2009).

A partir de 1990, um estranhamento queer surge em relação à teoria social, ou seja, aos estudos sociológicos, devido ao fato das ciências sociais tratarem a ordem social como sinônimo de heterossexualidade. O pressuposto heterossexista do pensamento sociológico era marcante nas investigações sobre sexualidades não-hegemônicas, e os estudos sobre as minorias acabavam por manter e neutralizar a norma heterossexual. Foi mediante este contexto que os primeiros teóricosqueer passaram a rejeitar a lógica minorizante dos estudos socioantropológicos em favor de uma teoria que questionasse os pressupostos normalizadores da Sociologia canônica (MISKOLCI, 2009).

A denominação QueerTheory, ou em português, Teoria Queer, foi empregada por Teresa de Lauretis da Universidade da Califórnia, em 1990, numa conferência de teorização das sexualidades lésbica e gay, com a intenção de contrastar esse novo campo teórico com os

\footnotetext{
${ }^{8}$ Tendência universal de se reduzir a raça humana a masculinidade, o homem como centro de tudo.
} 
estudos gays e lésbicos. A conferência foi pautada pela premissa teórica de que a homossexualidade não mais era definida por oposição ou homologia a uma forma de sexualidade estável e dominante (heterossexualidade), tampouco como uma mera transgressão ou desvio com relação a uma sexualidade correta ou normal (FILAX; SHOGAN, 2015; MISKOLCI, 2009).

Em termos políticos, o termo queer foi colocado como xingamento, que denotava perversão, anormalidade e desvio, passando a ser utilizado em movimentos críticos aos de caráter assimilacionista. Também acabou substituindo várias subjetividades que desafiam "o normal”, como lésbica, gay, bissexual, transexual e transgênero. Oqueersignifica colocar-se contra a normalização, seja de onde esta for. O seu alvo é a heteronormatividade compulsória da sociedade, assim, o queer representa claramente a diferença que não quer ser simplesmente assimilada ou tolerada, portanto, sua forma de ação é bastante transgressiva (LOURO, 2001; MISKOLCI, 2009).

Os estudos queertratam do problema de um ordenamento de dois sexos, dois gêneros e uma sexualidade, que em primeiro momento categoriza sistematicamente os seres humanos e depois os divide dentro de uma consideração daquilo que é normal e transviado. Portanto, a ideia de normalização é fundamental para a compreensão da importância da TeoriaQueer. Os estudos queer são voltados para os processos de normalização, como os que formulam categorias de raça, classe, aptidão física e idade atrelado ao contexto de lugar, cultura e tempo, e desenvolvem suas pesquisas através de experiências, discursos e identidades relacionadas a esta ordem sexual normalizadora (FILAX; SHOGAN, 2015).

Mediante esse contexto de identidades, Butler aponta que travestis e transexuais seriam justamente a subversão da ordem estabelecida, que abala a coerência compulsória. A autora se dedica, através dos atos subversivos, ao desmonte da heteronormatividade, conceito que expressa as expectativas, as demandas e as obrigações sociais que derivam do pressuposto da heterossexualidade como algo natural, bem como as prescrições que fundamentam processos sociais de regulação e controle, até mesmo para os que não se relacionam com pessoas do sexo oposto (JESUS, 2014).

Através de contribuições teóricas como a de Jacques Derrida, em que a heterossexualidade precisa da homossexualidade para sua própria definição, autores como Eve K. Sedgwig, David M. Halperin, Judith Butler e Michael Warner começaram a empreender análises sociais que retomavam a ideia de Foucault, ao estudar a sexualidade como dispositivo histórico do poder que marca as sociedades ocidentais modernas e é 
caracterizado pela interseção do sexo em sistemas de unidades e regulação social (MISKOLCI, 2009).

Para Butler, as reificações de gêneros e identidades cristalizam hierarquias e alimentam relações de poder, esse processo acaba por normalizar corpos e práticas, reproduzindo privilégios e exclusões. A normalização das identidades, atrelada a sua opressão, define padrões de comportamentos rejeitando as diferenças (PELÚCIO, 2012). Essa perspectiva de normalização de identidades e relações de poder pode ser claramente entendida nas palavras de Filax e Shogan (2015):

Para a heterossexualidade funcionar como o normal, natural e óbvio, é preciso que ela tenha seu outro anormal, antinatural, ausente: o homossexual. A desconstrução e a teoria psicanalítica fazem possível mostrar como se elabora a heteronormatividade mediante a exclusão do "outro" esquisito (FILAX; SHOGAN, 2015, p. 134).

Segundo Miskolci (2009), as alianças desenhadas entre os Estudos Pós-coloniais e a Teoria Queer parecem renascer a partir do nó de interseção que é formado pelas categorias de raça e sexualidade. Não se trata apenas de uma aliança estratégica, mas sim de um consenso de que as diversas formas de opressão priorizadas por cada linha de pesquisa são interdependentes em um mesmo processo de racialização do sexo e sexualização da raça. A conexão raça-sexualidade apresenta uma matriz essencializadora e subalternizante, que evidencia um processo normalizador que cria seres considerados menos humanos, até mesmo abjetos.

\subsection{Feminismos, origem e evolução dos movimentos no Norte global}

Segundo Stolcke (2004) a trajetória feminista é bastante singular, pois é uma história de relação bastante articulada entre um movimento político de emancipação pessoal e coletivo e um trabalho teórico inspirado pelo objetivo de identificar as raízes da opressão e desigualdade das mulheres como ferramentas de luta libertadora.

O feminismo tem sido estruturado em etapas históricas, que se dividem em três grandes fases. A primeira, chamada de fase universalista, humanista ou das lutas igualitárias pela aquisição de direitos civis, políticos e sociais; a segunda, chamada fase diferencialista e/ou essencialista, das lutas pela afirmação das diferenças e da identidade; e a terceira fase denominada de pós-moderna, derivada do desconstrucionismo, que deu apoio às teorias dos sujeitos múltiplos e/ou nômades. As três fases correspondem aos séculos XVIII a XIX, à segunda metade e ao final do século XX e ao início do século XXI (SCAVONE, 2008). 
O feminismo de primeira onda se desenvolve no final do século XIX, e é centrado na reivindicação por direitos políticos- como direito ao voto e de ser eleita-nos-direitos sociais e econômicos-como trabalho remunerado, estudo, propriedade e herança (PEDRO, 2005). Este feminismo inicial, que se deu tanto na Europa, Estados Unidos como também no Brasil, perdeu sua força a partir da década de 1930, e só ressurgiu com relevância a partir da década de 1960. (PINTO, 2010).

O feminismo chamado de segunda onda surge após a segunda guerra mundial, dando prioridade a luta pelos direitos do corpo, ao prazer e contra o patriarcado-entendido como o poder dos homens na subordinação das mulheres. Foi justamente na chamada segunda onda, que a categoria de gênero foi utilizada, como tributária das lutas do feminismo e do movimento das mulheres (PEDRO, 2005).

Diante do movimento crítico acerca da identidade feminina, onde se reivindicava uma diferença dentro da diferença, um desenvolvimento político paralelo a análise de gênero como sistema simbólico irá lidar com a reintrodução de experiências concretas de mulheres em diferentes contextos de poder e desigualdade nas teorias feministas. Na década de 1970, mulheres feministas negras nos Estados Unidos e Reino Unido se organizam para denunciar a opressão sexual, racial, heterossexual e de classe a que estão submetidas as mulheres negras em contraste com as mulheres brancas (STOLCKE, 2004).

Segundo Stolcke (2004), as feministas negras introduziram novo desafios políticos e teóricos. O engendramento das desigualdades sócio-raciais não são fruto de uma convergência ou fusão, de diferentes fontes de opressão sobre as mulheres, mas sim de uma interseção dinâmica entre o gênero, raça e classe em estruturas de dominação históricas.

Segundo Scavone (2008), a consolidação do campo de estudo sobre as mulheres, denominados de estudos de gênero, emergiu paralelamente a eclosão da fase contemporânea do feminismo, especialmente na Europa pós-68 e nos Estados Unidos. Foi a partir de então que o campo de investigação científico sobre as mulheres se ampliou evidenciando a forte relação dos movimentos sociais com os estudos feministas.

\subsection{Movimentos Feministas no Sul global}

Em vários países latino-americanos, a exemplo de Chile, Argentina, México, Peru e Costa Rica, bem como no Brasil, as primeiras manifestações feministas apareceram na primeira metade do século XIX. Na primeira década do século XX, já existiam organizações 
feministas socialistas, anarquistas e liberais em vários países da América Latina. É a partir dos anos 1920, que a luta sufragista toma forma em muitos dos países latino-americanos, liderada pelas mulheres de classe média e alta, que através de ações diretas com os órgãos legislativos, conquistam o direito do voto (TIMOTEO, 2013).

$\mathrm{Na}$ América Latina, a segunda onda do movimento feminista acontece nos anos de 1970, em meio ao autoritarismo e repressão dos regimes militares dominantes, além dos impactos do movimento feminista internacional (TIMOTEO, 2013).

Ao final dos anos de 1970, surge no Feminismo, críticas ao universalismo das propostas feministas que apontam a diferença sexual como causa da desigualdade de gênero. O universalismo feminista parte da ideia de que a diferença sexual é o problema e a solução seria atenuá-la através da independência das mulheres no que diz respeito ao trabalho, o abandono do confinamento do espaço doméstico e o questionamento dos papéis e ideologias da feminilidade (NAVAZ, 2008).

As novas propostas dão luz a um sujeito feminino com uma visão própria e particular que a distingue do homem e dá sentido enfim a categoria mulher em sua mais profunda e autêntica dimensão. Muitas mulheres pertencentes a coletivos situados a margem dos ativismos feministas dominantes denunciam o modo como seus interesses são cooptados pelo feminismo branco por uma parte, e por outra, como as representações das mulheres marcadas pela diferença étnica são racistas e enfraquecem o poder das mulheres. Feministas negras e mexicanas desde o contexto político norte-americano destacam a importância do racismo na invisibilização de seus interesses e apontam como proposta teórica tornar o sujeito analíticopolítico mais complexo (NAVAZ, 2008).

Segundo Navaz (2008), frente ao etnocentrismo do feminismo ocidental dominante, as vozes e experiências das mulheres excluídas impulsionam de várias formas para que o projeto político e intelectual do feminismo se descolonize, se democratize e consiga criar alianças necessárias para apoiar processos transformadores para as mulheres e homens das comunidades mais favorecidas e menos valorizadas do sul.

\section{Feminismos em África, o eurocentrismo no contexto da formação da identidade feminista africana}

Descritos como a era da modernidade, os últimos cinco séculos foram definidos por uma série de processos históricos, como o tráfico atlântico de escravos e instituições que 
acompanharam a escravidão, e também a colonização europeia de África, Ásia e América Latina. Foi durante esse período de grandes transformações que gênero e categorias de raça surgiram como dois eixos fundamentais ao longo dos quais as pessoas foram exploradas e sociedades estratificadas (OYĚWÙMÍ, 2004).

Um dos efeitos do eurocentrismo é a racialização do conhecimento, enquanto a Europa é representada como fonte do conhecimento, os europeus são como conhecedores. O privilégio do gênero masculino como uma parte essencial do ethos europeu está consagrado na cultura da modernidade (OYĚWÙMÍ, 2004).

Segundo Mohanty (2008), as estruturas jurídicas, econômicas, religiosas e familiares são tratadas como fenômenos suscetíveis ao julgamento do padrão ocidental, e é nesse contexto em que se encontra a universalidade eurocêntrica.

Existe uma evidência que sugere que o gênero, em toda sua diversidade e manifestações diversas, tem sido um dos princípios organizadores das sociedades africanas, do passado e do presente (MAMA, 2008). Tal evidência é reflexo das análises feministas que alimentam e mantêm a hegemonia da ideia de superioridade do ocidente, que acaba produzindo um conjunto de imagens universais da mulher do terceiro mundo (MOHANTY, 2008).

Segundo Mohanty (2008), a pressuposição de "mulheres" como um grupo já constituído e coerente, com interesses e desejos idênticos, sem se levar em consideração a classe social, ou a localização, ou as diferenças raciais e étnicas, implica em uma noção de diferença sexual ou de gênero, e até mesmo de patriarcado que pode ser aplicada de forma universal e a todas as culturas.

As pesquisadoras feministas usam gênero como o modelo explicativo para compreender a subordinação e a opressão sofrida pelas mulheres em todo mundo e, ao fazer isso, também assumem a categoria mulher e sua subordinação como universais. Contudo, gênero é antes de tudo uma construção sociocultural e, portanto, há que se questionar o porquê do uso desta categoria e não de raça, que é tão fundamental para afro-americanas (OYĚWÙMÍ, 2004).

Os estudos acadêmicos feministas do Ocidente sobre o Terceiro Mundo devem ser vistos e analisados em termos de sua inscrição dentro destas relações particulares de poder e luta. O feminismo ocidental não pode fugir da responsabilidade de se situar e analisar seu papel no contexto econômico e político global. Dessa forma, esse contexto global para a produção de conhecimento deve ser levado em consideração para se compreender as 
realidades africanas e de fato a condição humana (OYĚWÙMÍ, 2004). Não fazer tal reflexão, seria portanto, ignorar as complexas interconexões entre as economias de primeiro mundo e as de terceiro mundo, bem como seus profundos efeitos na vida das mulheres em todo o mundo (MOHANTY, 2008).

\subsection{0 caráter colonial do feminismo euro-americano no contexto africano: perspectivas locais}

Segundo Bakare-Yusuf (2003), dois encontros históricos e interdependentes são fundamentais para se analisar a experiência contemporânea do gênero africano. $O$ primeiro envolve a incorporação de diferentes sociedades africanas em uma economia mundial, que teve origem com a invasão mulçumana árabe no século VII, seguido pelo colonialismo europeu e a ocupação a partir do século $\mathrm{XV}$, que se estende até o presente sob forma de administrações neocoloniais contemporâneas. O segundo se baseia em um horizonte sóciocultural e metafísico africano da pré-conquista indígena, onde as identidades e relações sociais estão implicadas e incorporadas. Portanto, essas transformações que se seguem desde imposições internas e processos históricos internos se combinaram para distorcer, modificar e transformar as relações de gênero africanas, de tal modo que torna-se difícil falar sobre o significado e experiência da existência de gênero (BAKARE-YUSUF, 2003).

Segundo Bakare-Yusuf (2003), ao lidarmos com padrões específicos dentro de amplas trajetórias históricas, nossas investigações devem reconhecer que a cultura "nacional" de cada país africano é caracterizada por religiões, classes regionais, e especificidades étnicas. Um cuidado ao analisar cada contexto cultural africano nos permite reconhecer o poder da etnia em moldar a vida das pessoas, pois como afirma Herbert Ekwe-Ekwe, apesar da promoção dos Estados-nação na África:

a esmagadora maioria dos africanos ainda não vivem suas vidas cotidianas normais como senegaleses, nigerianos, zairenses, quenianos... Em vez disso, eles vivem suas vidas como Wolof, Yorùbá, Ibo, Ijo, Nupe, Bakongo, Baluba, Baganda, Kikuyu, Asante, e assim por diante (EKWE-EKWE,1993, p.95 apud BAKARE-YUSUF, 2003, p.14).

Para se evitar a definição "mulher africana" em termos de uma identidade unitária e fechada, um intervalo de elementos precisa ser situado nos termos de cada cultura. Só depois dessas análises iniciais é que se pode iniciar um diálogo intercultural significativo entre as mulheres africanas, para posteriormente, se possível, estender isso a outros grupos culturais com o objetivo de intercâmbios produtivos e libertadores dentro de uma comunidade global (BAKARE-YUSUF, 2003). 
O feminismo surge hoje com recorrência crescente em todas as formas de interação cultural, tanto enquanto teoria, atitude e até mesmo posicionamento. Posicionamento este que, sumariamente, visa a emancipação das mulheres da opressão política, econômica, cultural, social, física e fisiológica (BAMISILE, 2013).

Teóricas como NiaraSudarkasa, OyèrónkéOyěwùmí e NkiruNzegwu têm apontado que é errado sugerir que a assimetria sexual é interna a sociedades africanas, ou que gênero, antes da invasão europeia, era um princípio organizador, uma vez que as sociedades africanas podem muito bem ter suas próprias formas de desigualdades e estratificações. Dessa forma, autoras como Nzegwu apontam que equiparar diferença sexual com desigualdade sexual equivale a uma leitura equivocada das estruturas sociais africanas, bem como da importância do sexo dual. Assim, a noção de "patriarcado" é, portanto, visto como um conceito importado (BAKARE-YOSUF, 2003).

Apesar do feminismo ter se tornado global, é a família nuclear ocidental que fundamenta toda sua grande parte teórica, portanto, os conceitos centrais que tem sido os pilares do feminismo - gênero, mulher e sororidade - são apenas compreendidos de forma profunda quando se analisa a família nuclear da qual surgiram (OYĚWÙMÍ, 2004).

Segundo Oyewúmí (2004), o desafio central dos estudos de gênero africanos é a aplicação dos conceitos feministas para expressar e analisar as realidades africanas. $\mathrm{O}$ fato das categorias de gênero ocidentais serem apresentadas como inerentes a natureza biológica dos corpos, e operarem numa dualidade dicotômica binária, de homem/mulher, masculino/feminino, em que o homem é presumidamente superior, reside em uma questão particularmente alienígena a muitas culturas africanas.

\subsection{Feminismos em África: por uma epistemologia do Sul}

Ainda há pouca compreensão de que os arranjos sociais africanos, familiares e de outras formas são derivados de uma base conceitual completamente distinta. Em toda a África, a categoria iyawo, geralmente traduzida pelo inglês como esposa, não é um gênero específico, apenas denota relações de subordinação entre quaisquer duas pessoas. Assim, é bastante difícil confundir mulher com esposa e articulá-las como categoria dentro do esquema conceitual africano (OYĚWÙMÍ, 2000).

Sobre as características contrastantes dos sistemas familiares baseados em África e formas baseadas na Europa, a antropóloga NiaraSudarkasa ressalta que a família nuclear é 
uma família com bases conjugais, enquanto que na África ocidental, da qual a família Iorubá faz parte, é a linhagem que se considera como família. A linhagem familiar é um sistema baseado na consanguinidade, e é construída em torno de um núcleo de irmãos e irmãs (OYĚWÙMÍ, 2004).

A sociedade Iorubá do sudoeste da Nigéria apresenta um diferente tipo de organização familiar. Assim, a família tradicional Iorubá pode ser descrita como não generificada, uma vez que os papéis de parentesco e de categorias não são caracterizados ou diferenciados pelo gênero. Ao contrário do gênero, que é rígido e estático, o princípio da antiguidade é dinâmico e fluido (OYĚWÙMÍ, 2004).

De acordo com Bamisile (2013), os diferentes modos de expressão antifeministas no continente africano convergiram para a busca de alternativas de designações terminológicas para auto definição e luta pela emancipação das mulheres em África.

Tanto em África quanto na diáspora africana, as posições antifeministas se fazem bastante presentes e levaram a conceitualização de alternativas ao feminismo euro-americano. Podemos apontar como exemplo destes conceitos alternativos o "Motherism", proposto por Catherine Acholonu, o "Womanism" de Alice Walker, nos Estados Unidos, o Womanism de ChikwenyeOgunyemi e Mary Kolawole da Nigéria, o "Womanism" Africano de ClenoraHudsson-Weems dos E.U.A., o "Stiwanism" de MolaraOgundipe-Leslie da Nigéria, o conceito de "Misovire", cunhado por WerewereLiking, o conceito de "Femalism" de ChiomaOpara, e o de "Gynism", cunhado pela filósofa e feminista africana, Pauline Marie Eboh (BAMISILE, 2013).

Segundo Bamisile (2013), o que caracteriza comumente a grande preocupação de todas essas designações e todos esses conceitos é a busca e apresentação de um movimento autônomo das mulheres negras africanas. O objetivo é de que este movimento seja um contraponto ao feminismo euro-americano, dando corpo a crítica que as africanas pretendem fazer ao feminismo ocidental que exclusivamente depende do binarismo de gênero e suas consequências em termo de desvalorização da mulher.

O conceito de "Motherism", desenvolvido pela estudiosa Acholonu, de origem nigeriana, defende a ideia de que nas sociedades tradicionais africanas as mulheres não estavam em situação de desvantagem em relação aos homens. Segundo a autora, a noção de que as mulheres estão em situação de inferioridade em relação aos homens foi importada para África, através do colonialismo ocidental e árabe, e se deu em resultado do impacto de 
posicionamentos discriminatórios provenientes das ideologias cristã e islâmica (BAMISILE, 2013).

Acholonu (1998 apud BAMISILE, 2013) considera que a deliberada marginalização das mulheres foi uma das principais estratégias do colonialismo, uma vez que os colonialistas tinham consciência da importância e influência das mulheres, bem como da força das sociedades africanas, derivadas da coesão de um tecido social em que os sexos coexistiam em complementaridade. Portanto, para esta autora não faz sentido as mulheres africanas adotarem as ideologias feministas ocidentais, sem levarem em conta a especificidade cultural e histórica de suas peculiares experiências de vida em África e da visão de mundo daí decorrente.

Para Acholonu (1995 apud BAMISILE, 2013), a conceituação de um feminismo africano deve incluir a aceitação e inclusão da condição de mãe, onde o conceito "Motherism", congrega e incorpora as noções de maternidade, natureza e sustento, e tanto homens quanto mulheres podem ser "Motherists".

Outro conceito surge com a autora Opara (1999), intitulado "Femalism", em que a autora defende a solidariedade e colaboração entre os sexos. Este conceito é similar ao de "Gynismo", desenvolvido pela filósofa e feminista africana Eboh (1999), onde a autora sublinha a igualdade dos homens e das mulheres a partir da perspectiva divina da complementaridade dos sexos. Há também o conceito proposto pela nigeriana MolaraOgundipe-Leslie, intitulado de "Stiwanism", este conceito chama atenção para a inclusão das mulheres africanas, com a participação dos homens, nos processos de transformação política e social, refletido a partir do acrônimo STIWA, criado pela autora para designar Social TransformationIncludingWomen In Africa. Esse conceito não é bem aceito na África por refletir tendências de imposição imperial e neocolonial (BAMISILE, 2013).

A alternativa feminista mais conhecida é a de "Womanism", proposta pela escritora afro-americana, Alice Waker, que defende um caráter universalista pela luta das mulheres, porém defende também a necessidade de um conceito específico focado na identidade das mulheres negras. As "womanists" defendem estão empenhadas em superar a discriminação sexista, mas também a discriminação de identidade social e socioeconômicadas pessoas (BAMISILE, 2013).

Segundo Eboh (1998), as mulheres africanas reconhecem a necessidade de um feminismo internacional, porém, elas rejeitam o modelo ocidental feminista. Apesar das demandas feministas dos países ocidentais serem igualmente relevantes para as mulheres africanas, estas dificilmente querem ser associadas ao termo "feministas", elas preferem ser 
reconhecidas por "Womanists". A filosofia do "Womanism" africano é a fidelidade tanto a emancipação das mulheres quanto a libertação da África.

O conceito de Womanism, da nigeriana ChikwenyeOkonjoOgunyemi, também descreve o movimento como uma emanação negra do feminismo, contudo, apesar de ambos movimentos lutarem pela liberdade e independência das mulheres, devem ser postos em prática de formas diferentes no Norte branco e Sul negro global. Isso se dá porque o "Womanism" é uma forma de feminismo que supera questões de gênero, adentrandono âmbito das questões de raça e classe social. Neste sentido, a autora defende a exclusividade da participação das mulheres negras neste movimento e por este motivo, esse movimento nunca se associou ao "Womanism" de Alice Waker (BAMISILE, 2013).

Há também o conceito de Africana "Womanism", desenvolvido pela afro-americana Clenora Hudson-Weems, uma ideologia criada e destinada a todas as mulheres de ascendência africana. A autora também defende exclusividade para as mulheres negras neste movimento, pois defende que a verdadeira história do feminismo revela um fundo de caráter racista e, portanto, incompatível com as mulheres africanas (BAMISILE, 2013).

Em meio as diferenças de gênero que são fundamentadas nas complexas realidades das experiências cotidianas das mulheres africanas, os feminismos africanos passam a exigir uma descrição teórica mais incorporada, que leve esses fatores em consideração (BAKAREYUSUF, 2003).

Exemplos africanos, como a família Iorubá, refletem os desafios ao universalismo injustificados de discursos de gênero feministas. A partir deste exemplo, torna-se completamente claro que as categorias sociais africanas são fluidas, não se baseiam no tipo de corpo e são altamente situacionais. Portanto, as análises e interpretações de África, devem partir da África, tanto significados quanto interpretações devem derivar das relações sociais e da organização social, levando em consideração os contextos culturais e locais específicos (OYĚWÙMÍ, 2004).

Os cinco séculos de longo processo de globalização implicaram em uma série diversa de fronteiras em todo o globo. Uma das questões mais importantes para o feminismo na virada do milênio, é a fragmentação da mulher - o sujeito do feminismo. Isso pode ser entendido como um desafio lançado pelas bases pós-modernistas da (ir)realidade social. Os desafios teóricos para a compreensão racial e cultural monolítica do sujeito pós-moderno são anteriores ao feminismo. As feministas negras americanas são exemplos disso (OYĚWÙMÍ, 2004). 
O que se faz necessário é um movimento a margem das construções monolíticas, que esteja voltado para esforços que lidem com a experiência vivida em todas as suas ramificações existenciais. Ao caminharmos nesse sentido, poderemos fornecer descrições mais abrangentes e completas sobre as identidades das mulheres africanas em toda sua rica complexidade (BAKARE-YUSUF, 2003).

\section{Considerações Finais}

Como se pode constatar na presente pesquisa, os feminismos ocidentais em sua totalidade não se reportam as mulheres do Sul global de forma plena. As questões de gênero e sexualidade ainda carregam traços de colonialidades, até mesmo dentro dos movimentos feministas euro-americanos, não abarcando questões fundamentais - como raça, classe, etnia, sexualidade-que dizem forte respeito ao Sul global, reproduzindo assim as colonialidades. Conceitos feministas como o Womanism, da nigeriana ChikwenyeOkonjo, e o Motherism, da também nigeriana Acholonu, são conceitos que se aproximam das características do pensamento fronteiriço, e portanto, apresentam certo caráter de pensamento descolonial.

Se faz necessário que os movimentos feministas africanos continuem se fortalecendo, delimitando seus próprios conceitos e identidades através de suas próprias concepções de mundo, pois só assim, as mulheres africanas alcançarão sua legitimidade e efetividade nas lutas pela emancipação política e libertação do julgo colonial.

\section{Referências}

BAKARE-YUSUF, Bibi. Beyond Determinism: The Phenomenology of African Female Existence. FeministAfrica, 2003.

BALlenstrin, L. América Latina e o Giro Decolonial. Revista brasileira de Ciência Política, no 11. Brasília, maio-agosto,p. 89-117, 2013.

BAMISILE, SundayAdetunji. A procura de uma ideologia afro-cêntrica: do feminismo ao afro-feminismo. Via Atlântica, São Paulo, nº 24, pp. 257-279, dez, 2013.

DONATO, Manuela; MELO, Vico. Por que Feminismo nas Relações Internacionais? Uma breve análise acerca das contribuições das teorias feministas à compreensão da política internacional. In: VI Seminário de Ciência Política e Relações Internacionais, 2010, Recife. Anais do VI Seminário de Ciência Política e Relações Internacionais, 2010.

ElíBio Jr, A. M.; ALMEIDA, C. S. D. M. de.; LIMA, M. C. Edward Said e o Póscolonialismo.Saeculum-Revista de História, no 29, João Pessoa, jul/dez, 2013. 
FILAX, Gloria; SHOGAN, Debra. Teoria Queer/Abordagens Lésbica e Gay. In: SOMEKH, Bridget; LEWIN, Cathy (orgs). Teoria e Métodos de Pesquisa Social. Vozes, 2015.

FONSECA, M.; JERREMS, A. Pensamiento Decolonial: uma nuevaapuestaenlas Relaciones Internacionales. Relaciones Internacionales, nº 19, fev, 2012.

GROSFOGUEL, Ramon. "Para descolonizar os estudos de economia política e os estudos pós-coloniais: transmodernidade, pensamento de fronteira e colonialidade global". Revista Crítica de Ciências Sociais, n. 80, p. 115-147, 2008.

LOURO, Guaciara Lopes. Teoria queer: uma política pós-identitária para a educação. Revista de Estudos Feministas, Florianópolis, v. 9, n. 2, 2001.

LUGONES, María. Rumo a um feminismo descolonial. Revista Estudos Feministas, v. 2, no 03, p. 935-952, 2014.

MALDONADO-TORRES, Nelson. Sobre lacolonialidaddel ser: contribuciones al desarrollo de um concepto. In: El giro decolonial: reflexiones para una diversidad epistémica más alládel capitalismo global. Santiago Castro-Gómez y Ramón Grosfoguel. - Bogotá: SiglodelHombre Editores; Universidad Central, Instituto de EstudiosSocialesContemporáneos y PontificiaUniversidadJaveriana, Instituto Pensar, 2007.

MAMA, Amina. Temas desafiantes: Género y Poder enlos Contextos Africanos. In: SUÁREZ, Navaz L.; HERNÁNDEZ, Rosalva (Ed). Descolonizando El Feminismo: Teorías y Prácticas desde losMárgenes, 2008.

MIGNOLO, Walter. Desobediencia epistémica: retórica de lamodernidad, lógica de lacolonialidad y gramática de ladescolonialidad. Argentina: Edicionesdel signo, 2010.

Walter. Historias locales/disenosglobales: colonialidad, conocimientos subalternos y pensamientofronterizo. Madrid: Akal, 2003.

MISKOLCI, Richard. A Teoria Queer e a Sociologia: o desafio de uma analítica da normalização. Sociologias, ano 11, nº 21, pp. 150-182, Porto Alegre, jan/jun, 2009.

MOHANTY, ChandraTalpade. Bajoslosojos de Occidente Academia Feminista y discurso colonial. In: SUÁREZ, Navaz L.; HERNÁNDEZ, Rosalva (Ed). Descolonizando El Feminismo: Teorías y Prácticas desde losMárgenes, 2008.

NAVAZ, Liliana Suárez. Colonialismo, Gobernabilidad y Feminismos Poscoloniales. In: SUÁREZ, Navaz L.; HERNÁNDEZ, Rosalva (Ed). Descolonizando El Feminismo: Teorías y Prácticas desde losMárgenes, 2008.

OYĚWÙMÍ, Oyèrónké. Conceptualizing Gender: The Eurocentric Foundations of Feminist Concepts and the challenge of African Epistemologies. African Gender Scholarship: Concepts, Methodologies and Paradigms. CODESRIA Gender Series. Volume 1, Dakar, 2004.

Oyèronké. Family bonds/Conceptual Binds: African notes on Feminist Epistemologies.Signs, Vol. 25, No. 4, pp.1093-1098, Feminismsat a Millennium, 2000. 
PEDRO, Joana Maria. Traduzindo o debate: o uso da categoria gênero na pesquisa histórica. História, São Paulo, v. 24, n. 1, pp. 77-98, 2005.

PELÚCIO, Larissa. Subalterno quem, cara pálida? Apontamentos às margens sobre póscolonialismos, feminismos e estudos queer. Contemporânea-Dossiê Saberes Subalternos, v.2, nº 02, pp. 263-369, 2012.

PINTO, Céli Regina Jardim. Feminismo, História e Poder. Revista de Sociologia e Política, v. 18, n⿳30, Jun, pp.15-23, 2010.

QUIJANO, Aníbal. Colonialidaddel poder y clasificación social. In: El giro decolonial: reflexiones para una diversidad epistémica más alládel capitalismo global. Santiago Castro-Gómez y Ramón Grosfoguel. - Bogotá: SiglodelHombre Editores; Universidad Central, Instituto de EstudiosSocialesContemporáneos y PontificiaUniversidadJaveriana, Instituto Pensar, 2007.

SANTOS, G. G. da C.; SILVA, M. de A. Gênero, Sexualidade e Pós-colonialidade. Realis, v. $4, \mathrm{n}^{\circ} 01$, jan/jun, 2014.

SCAVONE, Lucila. Estudos de gênero: uma sociologia feminista. Estudos feministas,

Florianópolis, pp. 173-186, jan/abr, 2008.

SOIHET, Rachel. História, mulheres, gênero: contribuições para um debate.In: NEUMA, Aguiar (org.) Gênero e Ciências Humanas. RJ, Rosa dos Tempos, 1997.

STOLCKE, Verena. La mujer es puro cuento: la cultura del género. Estudos Feministas, Florianópolis, pp. 77-105, maio/ago, 2004.

TIMOTEO, Carolina Quieroti. As transformações do movimento feminista no Brasil e sua relação com a América Latina. In: V Simpósio Internacional Lutas Sociais na América Latina, 2013.

TRUE, Jacqui. Feminism. In: BURCHILL, Scott et al. Theories of International Relations.2. ed. Nova Iorque: Palgrave, 1996. 